\title{
Pengenalan Konsep Ergonomi Dapur Kepada Ibu- Ibu PKK Kelurahan Sukawarna Kecamatan Sukajadi Kota Bandung dengan Pendekatan Edukatif dan Partisipatif
}

\author{
Novi $^{* 1}$, Elty Sarvia ${ }^{* 2}$, Wawan Yudiantyo ${ }^{* 3}$, Winda Halim ${ }^{* 4}$, Christina ${ }^{* 5}$ \\ *Program Studi Teknik Industri, Fakultas Teknik, Universitas Kristen Maranatha \\ Prof. Drg. Suria Sumantri, No.65, 40164, Sukawarna, Kec. Sukajadi, Kota Bandung, Jawa Barat 40164 \\ 1novi@eng.maranatha.edu, ${ }^{2}$ elty.sarvia@eng.maranatha.edu \\ ${ }^{3}$ wawan.yudiantyo@eng.maranatha.edu,${ }^{4}$ winda.halim@eng.maranatha.edu \\ ${ }^{5}$ christina@eng.maranatha.edu
}

\begin{abstract}
Abstrak - Saat ini pandemi Covid 19 yang masih menjangkiti hampir semua negara di dunia menyebabkan perubahan besar pada gaya hidup. Sekarang orang cenderung lebih memperhatikan asupan makanan dan kebersihannya. Selain itu, karena banyak menghabiskan banyak waktu di rumah maka muncul kebiasaan baru pula, salah satunya adalah kegiatan memasak di dapur. Berdasarkan survei yang dilakukan, $87 \%$ peserta menghabiskan waktunya lebih dari 1 jam di dapur. Tetapi sayangnya, masih banyak ketidaktahuan tentang bagaimana kondisi dapur yang ergonomis. Hal ini terbukti dari kuesioner yang diisi sebelum penyampaian informasi dilakukan. Seluruh peserta yang berjumlah 15 orang yang berasal dari PKK Kelurahan Sukawarna Kecamatan Sukajadi Kota Bandung belum mengenal istilah ergonomi dan penerapannya di dapur. Pengabdian masyarakat ini bertujuan untuk mengenalkan konsep ergonomi dapur kepada ibu-ibu PKK sehingga mereka dapat bekerja dengan lebih aman, sehat, nyaman, efektif, dan efisien. Metode yang digunakan adalah dengan pendekatan edukatif berbentuk webinar yang dilaksanakan secara daring. Kemudian, dilanjutkan dengan pendekatan partisipatif dengan memberikan kesempatan pada peserta untuk mengevaluasi dapurnya saat ini. Melalui edukasi yang disampaikan terlihat hasil berupa peningkatan pengetahuan peserta terkait konsep ergonomi dapur dan peserta dapat menjawab pertanyaanpertanyaan terkait penerapan ergonomi di dapur dengan lebih baik. Serta melalui pendekatan partisipatif yang dilakukan peserta menyadari kekurangan dapurnya saat ini. Hasil yang diharapkan adalah para peserta dapat lebih memperhatikan kondisi dapurnya sehingga dapat bekerja di dapur dengan lebih aman dan terhindar dari bahaya kecelakaan kerja.
\end{abstract}

Kata kunci-edukasi, ergonomi dapur, pastisipatif, kuesioner.

Abstract-Currently the Covid 19 pandemic which is still infecting almost all countries in the world has caused major changes in lifestyle. Now people tend to pay more attention to food intake and hygiene. In addition, because they spend a lot of time at home, new habits also appear, namely cooking in the kitchen. Based on a survey conducted $87 \%$ of participants spend more than 1 hour in the kitchen. But unfortunately, there is still a lot of ignorance about how the ergonomic conditions of the kitchen are. It was proven by the questionnaire which filled out before the deliveries of information. All of the 15 participants from PKK Kelurahan Sukawarna Kecamatan Sukajadi Bandung City were not familiar with the term of ergonomics and its application in the kitchen. This community service aims to introduce the concept of kitchen ergonomics to PKK womens so that they can work more safely, healthily, comfortably, ef ectively, and ef iciently. The method used is an educational approach in the form of webinars which are held online. Then, followed by a participatory approach by giving participants the opportunity to evaluate their current kitchen. Through the education delivered, the results showed an increase in participants' knowledge regarding the concept of kitchen ergonomics and they were able to answer questions related to the application of ergonomics in the kitchen better. And through a participatory approach, participants are aware of the shortcomings of their current kitchen. The expected result is that the participants can pay more attention to the condition of their kitchen so that they can work in the kitchen more safely and avoid the dangers of work accidents.

Keywords-educational, kitchen ergonomic, participatory, survey

\section{Pendahuluan}

Pandemi Covid 19 telah menjangkiti hampir seluruh negara di dunia selama lebih dari satu setengah tahun. Pandemi ini mengubah banyak hal dalam gaya hidup, baik terkait mobilitas, transaksi jual beli, aktivitas belajar 
mengajar, dan masih banyak lagi. Anjuran pemerintah untuk melaksanakan protokol kesehatan yaitu $5 \mathrm{M}$ (Menjaga jarak, Mencuci tangan, Menggunakan masker, Membatasi mobilitas, dan Menjauhi kerumunan) mengharuskan banyak orang untuk menghabiskan banyak waktu di rumah.

Keharusan untuk tetap tinggal di rumah menyebabkan banyak orang mencari cara untuk menghabiskan waktunya dengan berbagai aktivitas, antara lain memasak, berkebun, berolahraga, dan lainnya. Aktivitas memasak selain dilakukan untuk menghabiskan waktu juga dilakukan untuk dapat menghasilkan makanan yang lebih sehat dan bersih untuk anggota keluarga. Berdasarkan penelitian yang dilakukan oleh [1], hampir 74,1\% respondennya memilih untuk memasak sendiri daripada membeli dari luar. Tempat yang berkaitan erat dengan aktivitas ini tentu saja adalah dapur rumah. Rancangan dapur rumah di Indonesia biasanya belum memenuhi aspek ergonomis karena banyak perumahan membangun ruang dapurnya dengan bentuk dan ukuran yang seragam tanpa melihat dimensi dari penggunanya. Akibatnya orang yang lebih pendek atau lebih tinggi tidak sesuai dengan ukuran dengan fasilitas dapur [2]

Berdasarkan survei yang dilakukan pada saat pengabdian masyarakat ini dilakukan hampir $87 \%$ responden menghabiskan waktu di dapur lebih dari 1 jam. Tetapi, sayangnya hampir seluruh responden yang berasal dari Ibu-ibu PKK Kelurahan Sukawarna Kecamatan Sukajadi Kota Bandung ini tidak mengenal konsep ergonomi dapur dan pentingnya penerapannya untuk menjaga efisiensi, efektifitas, kesehatan, keamanan, dan kenyamanan mereka saat melakukan aktivitasnya di dapur.

\section{MASALAH}

Permasalahan yang ada, seringkali desain dapur belum memperhatikan kenyamanan penggunanya. Padahal desain dapur yang tidak ergonomis, terutama ketika digunakan dalam jangka waktu yang lama, dapat menyebabkan berbagai efek negatif seperti cepat timbulnya kelelahan, keluhan terkait kesehatan seperti sakit punggung [3], juga resiko kecelakaan saat bekerja di dapur. Keamanan untuk bekerja di dapur juga sangat penting terutama untuk orang lanjut usia [4].

Beberapa bahaya yang dapat muncul saat bekerja di dapur dapat dikelompoknya menjadi 10 jenis antara lain, teriris pisau (knife cuts), bahaya terbakar (burn hazards), luka akibat mesin (injury from machine), terpeleset, tersandung, dan terjatuh (slip, trip, and falls), luka akibat pengangkatan (lifting injuries), luka kepala dan mata (head and eyes injuries), resiko tempat kerja yang sesak (crowded workspace risks), bahaya kimia (chemical hazards), bahaya api (fire hazards), dan sengatan listrik (electric shock) [5]

\section{METODE PELAKSANAAN}

Berdasarkan survei pendahuluan diketahui bahwa masih minimnya pengetahuan Ibu-ibu PKK Kelurahan Sukawarna Kecamatan Sukajadi Kota Bandung ini terkait dengan ergonomi khususnya ergonomi dapur, maka pengabdian masyarakat ini diawali dengan melakukan pendekatan edukatif dengan memberikan penyuluhan terkait apa yang dimaksud dengan ergonomi, penerapan ergonomi di dapur, tata letak yang ergonomis, serta berbagai peralatan yang ergonomis. Kemudian dilanjutkan dengan pendekatan partisipatif agar Ibu-ibu PKK ini dapat menerapkan hal-hal yang dipelajari untuk mengevaluasi dapurnya saat ini dan dapat membuat rancangan dapurnya lebih ergonomis. Penyuluhan ini dilakukan oleh 4 dosen Teknik Industri yang tergabung dalam kelompok bidang keahlian Perancangan Produk dan Ergonomi. Pengumpulan data dilakukan sebelum pemaparan materi yang bertujuan untuk mengetahui tingkat pengetahuan dan informasi yang dimiliki oleh peserta.

Pengumpulan data awal ini dilakukan dengan membagikan kuesioner di tempat acara berlangsung. Setelah itu, dilakukan juga survei setelah acara berakhir pada hari kedua, untuk mengukur seberapa efektif penyampaian materi yang dilakukan. Pendekatan edukatif dan partisipatif ini dilakukan untuk dapat memastikan bahwa informasi dapat sampai dan diserap dengan mudah oleh peserta, serta dapat langsung dibahas penerapannya secara langsung.

Data yang diperoleh kemudian akan diolah secara deskriptif untuk mengetahui jumlah atau prosentase secara kuantitatif dari kondisi yang ada. Selain itu, data yang diperoleh juga dibandingkan antara kondisi sebelum penyampaian materi dan sesudah seluruh acara selesai.

Pengabdian masyarakat ini dilaksanakan saat pandemi berlangsung, sehingga pelaksanaannya dilakukan secara daring menggunakan platform Zoom. Acara ini dilaksanakan pada 10 dan 24 Juni 2021, masing-masing selama kurang lebih 1,5 jam. Pada hari pertama dilakukan survei pendahuluan, penyampaian materi, dan penyampaian tugas yang harus dilakukan oleh peserta. Tugas yang diberikan berkaitan dengan format pendekatan partisipatif yang akan dilaksanakan pada hari kedua. Tugas yang dimaksud adalah peserta diharuskan untuk memotret dapurnya saat ini, dan melakukan evaluasi terhadap kondisinya saat ini. Tugas ini berkaitan erat dengan metode pendekatan partisipatif yang ingin diterapkan. Pada hari kedua setelah didahului dengan penyampaian materi tambahan, peserta kemudian mempresentasikan kondisi dapurnya saat ini dan mencoba untuk melakukan evaluasi. Kami sebagai fasilitator memberikan arahan dan masukan untuk dapat membuat dapur yang ditampilkan melalui gambar foto tersebut lebih baik

\section{HASIL DAN PEMBAHASAN}


Pengabdian masyarakat ini dilakukan selama 2 hari yaitu pada 10 Juni 2021 dan 24 Juni 2021. Pada 10 Juni 2021 ibuibu PKK Kelurahan Sukawarna Kecamatan Sukajadi Kota Bandung berkumpul di aula kelurahan dengan tetap memperhatikan protokol kesehatan secara ketat, sedangkan penyampaian materi dilakukan melalui media Zoom Meeting. Suasana aktivitas pada hari pertama dapat dilihat pada Gambar 1.

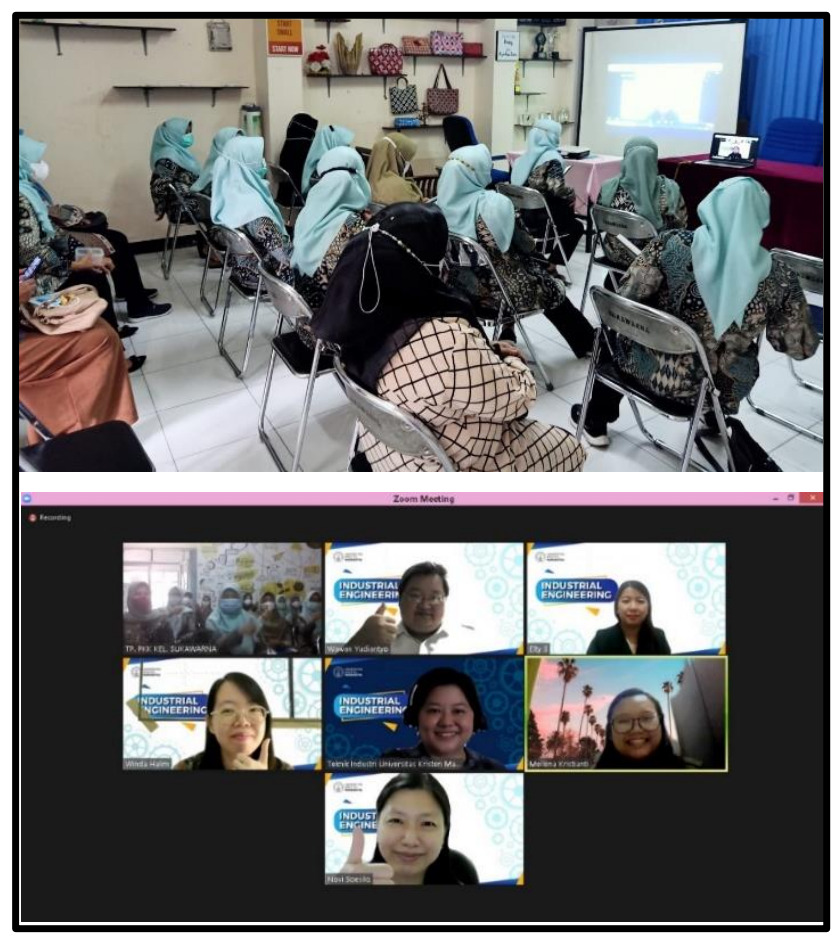

Gambar 1. Pelaksanaan Hari Pertama (10 Juni 2021)

Pelaksanaan hari pertama pengabdian masyarakat ini didahului dengan melakukan survei pendahuluan. Survei ini terbagi menjadi 2 bagian, pada bagian pertama ingin diketahui berbagai hal yang berkaitan dengan profil responden saat melakukan aktivitasnya di dapur, sedangkan pada bagian kedua ingin dilakukan pemetaan terkait pengetahuan yang dimiliki oleh responden sebelum penyampaian materi dilakukan. Hasil yang diperoleh dari survei pendahuluan bagian pertama dapat dilihat pada Tabel 1.

TABEL I.

HASIL SURVEI BAGIAN 1

\begin{tabular}{|c|c|c|c|c|}
\hline $\begin{array}{c}\text { N } \\
\text { o }\end{array}$ & Pertanyaan & \multicolumn{3}{|c|}{ Pilihan Jawaban } \\
\hline \hline \multirow{2}{*}{1} & $\begin{array}{c}\text { Apakah } \\
\text { Bapak/Ibu } \\
\text { Pernah }\end{array}$ & Pernah & $\begin{array}{c}\text { Tidak } \\
\text { Pernah }\end{array}$ & \\
\cline { 3 - 4 } & $\begin{array}{c}\text { Mendengar } \\
\text { istilah Ergonomi? }\end{array}$ & 0 & 15 & \\
\hline \multicolumn{2}{|c|}{ Prosentase } & $0 \%$ & $100 \%$ & \\
\hline
\end{tabular}

\begin{tabular}{|c|c|c|c|c|c|}
\hline \multirow[b]{2}{*}{2} & \multirow{2}{*}{$\begin{array}{c}\text { Berapa lama } \\
\text { kira-kira } \\
\text { bapak/ibu } \\
\text { menghabiskan } \\
\text { waktu di dapur } \\
\text { per hari? }\end{array}$} & $\begin{array}{l}<1 \\
\text { Jam }\end{array}$ & 1-2 Jam & $\begin{array}{l}2-3 \\
\text { Jam }\end{array}$ & $\begin{array}{c}\text { Lainny } \\
\text { a }\end{array}$ \\
\hline & & 2 & 4 & 7 & 2 \\
\hline \multicolumn{2}{|r|}{ Prosentase } & $13 \%$ & $27 \%$ & $47 \%$ & $13 \%$ \\
\hline \multirow[b]{2}{*}{3} & \multirow{2}{*}{$\begin{array}{c}\text { Apakah } \\
\text { Bapak/Ibu } \\
\text { memiliki keluhan } \\
\text { setelah bekerja di } \\
\text { dapur? } \\
\end{array}$} & Sering & $\begin{array}{c}\text { Kadang- } \\
\text { kadang }\end{array}$ & Jarang & $\begin{array}{c}\text { Tidak } \\
\text { Pernah } \\
\end{array}$ \\
\hline & & 1 & 12 & 0 & 2 \\
\hline \multicolumn{2}{|r|}{ Prosentase } & $7 \%$ & $80 \%$ & $0 \%$ & $13 \%$ \\
\hline \multirow[b]{2}{*}{4} & \multirow{2}{*}{$\begin{array}{c}\text { Apakah } \\
\text { Bapak/Ibu } \\
\text { Memahami } \\
\text { penerapan } \\
\text { Ergonomi dapur } \\
\text { yang baik? }\end{array}$} & Ya & Tidak & & \\
\hline & & 2 & 13 & & \\
\hline \multicolumn{2}{|r|}{ Prosentase } & $13 \%$ & $87 \%$ & & \\
\hline \multirow[b]{2}{*}{5} & \multirow{2}{*}{$\begin{array}{c}\text { Apakah saat ini } \\
\text { Bapak/Ibu } \\
\text { merasa tidak } \\
\text { nyaman dengan } \\
\text { desain dapur } \\
\text { yang dimiliki? }\end{array}$} & $\mathrm{Ya}$ & Tidak & & \\
\hline & & 9 & 6 & & \\
\hline \multicolumn{2}{|r|}{ Prosentase } & $60 \%$ & $40 \%$ & & \\
\hline \multirow[b]{2}{*}{6} & \multirow{2}{*}{$\begin{array}{c}\text { Apakah } \\
\text { Bapak/Ibu } \\
\text { memiliki rencana } \\
\text { untuk menata } \\
\text { ulang dapur } \\
\text { sehingga menjadi } \\
\text { lebih baik dan } \\
\text { nyaman? }\end{array}$} & Ya & Tidak & & \\
\hline & & 13 & 2 & & \\
\hline \multicolumn{2}{|r|}{ Prosentase } & $87 \%$ & $13 \%$ & & \\
\hline \multirow[b]{2}{*}{7} & \multirow{3}{*}{$\begin{array}{c}\text { Apakah } \\
\text { Bapak/Ibu } \\
\text { tertarik dengan } \\
\text { judul PKM } \\
\text { "Ergonomi } \\
\text { Dapur?" } \\
\text { Prosentase }\end{array}$} & Ya & Tidak & & \\
\hline & & 15 & 0 & & \\
\hline & & $100 \%$ & $0 \%$ & & \\
\hline
\end{tabular}

Berdasarkan hasil survei tersebut dapat terlihat bahwa masih minim pengetahuan yang dimiliki oleh ibu-ibu PKK terkait ergonomi karena hampir seluruh peserta ternyata belum pernah mendengarnya. Ergonomi dapat didefinisikan sebagai suatu disiplin ilmu yang mengkaji keterbatasan, kelebihan, serta karakteristik manusia, dan memanfaatkan informasi tersebut dalam merancang produk, mesin, fasilitas, lingkungan dan bahkan sistem kerja, dengan tujuan utama tercapainya kualitas kerja yang terbaik tanpa mengabaikan aspek kesehatan, keselamatan, serta kenyamanan manusia sebagai penggunanya [6].

Jika dlihat dari hasil survei, tampak bahwa hampir $87 \%$ peserta menghabiskan waktunya di dapur lebih dari 1 jam dan mereka memiliki keluhan saat bekerja di dapur. Survei tersebut juga memperlihatkan bahwa hanya $13 \%$ yang telah memahami penerapan ergonomi di dapur yang baik, padahal mereka sudah merasakan ketidaknyamanan saat bekerja di dapur $(60 \%)$ dan berencana untuk melakukan 
penataan ulang dapurnya agar dapat digunakan lebih nyaman $(87 \%)$. Kondisi ketidaksesuaian meja, peralatan kerja, fasilitas di area dapur tidak hanya berdampak pada ketidaknyaman penggunanya, tetapi juga berdampak pada hal negatif lainnya seperti kelelahan yang cepat terjadi, produktivitas yang menurun, dan potensi kecelakaan yang akan terjadi.

Manusia memiliki dimensi fisik yang beragam. Antropometri adalah pengukuran yang terfokus pada dimensi tubuh manusia. Faktor-faktor yang mempengaruhi data antropometri antara lain: 1) Jenis Kelamin 2) Ras dan Etnis 3) Usia 4) Jenis pekerjaan dan Aktivitas 5) Kondisi sosio ekonomi [7] [8]. Banyak hal yang wajib diperhatikan dalam membuat area dapur ergonomis. Mulai dari penataan kitchen set, pemilihan kitchen sink, ukuran meja kerja, lemari penyimpanan yang pas bagi pemilik dapur, sirkulasi udara dan pencahayaan [9]

Pada kuesioner bagian 2 ingin dilakukan pemetaan terkait pengetahuan peserta terkait materi yang ada sebelum penyampaian dilakukan dengan menanyakan beberapa pertanyaan yang dapat dilihat pada Tabel 2 .

TABEL 2.

HASIL SURVEI BAGIAN 2

\begin{tabular}{|c|l|c|}
\hline No & \multicolumn{1}{|c|}{ Pertanyaan } & Persentase \\
\hline 1 & Apa yang dimaksud dengan Ergonomi & $0 \%$ \\
\hline 2 & $\begin{array}{l}\text { Apakah yang menjadi fokus perancangan dalam } \\
\text { ergonomi }\end{array}$ & $67 \%$ \\
\hline 3 & $\begin{array}{l}\text { Berdasarkan Ilmu Ergonomi, apa yang harus kita } \\
\text { perhatikan dalam merancang produk? }\end{array}$ & $33 \%$ \\
\hline 4 & $\begin{array}{l}\text { Hal-hal yang perlu diperhatikan dalam merancang } \\
\text { dapur yang ergonomis? }\end{array}$ & $73 \%$ \\
\hline 5 & $\begin{array}{l}\text { Saat menyimpan peralatan elektrik di dapur harus } \\
\text { memperhatikan? }\end{array}$ & $93 \%$ \\
\hline 6 & $\begin{array}{l}\text { Apa yang perlu diperhatikan dalam penggunaan } \\
\text { tabung gas? }\end{array}$ & $40 \%$ \\
\hline 7 & $\begin{array}{l}\text { Apa yang perlu diperhatikan dalam perancangan } \\
\text { lingkungan fisik di area dapur? }\end{array}$ & $20 \%$ \\
\hline
\end{tabular}

Pada hasil survei bagian 2 dapat terlihat bahwa prosentase peserta untuk dapat memberikan jawaban yang benar masing sangat beragam. Tetapi yang menjadi perhatian khusus adalah hampir semua peserta tidak memahami apa yang dimaksud dengan ergonomi, tidak mengetahui hal yang penting dalam merancang produk, hal yang harus diperhatikan dalam penggunaan tabung gas, dan hal-hal yang penting dalam merancang lingkungan fisik dapur yang baik, karena jawaban dari pertanyaan tersebut masih memiliki prosentase yang cukup rendah. Setelah pembagian kuesioner dilakukan penyampaian materi yang dilakukan oleh dosen-dosen dari KBK Perancangan Produk dan Ergonomi terkait dengan ergonomi, ergonomi dapur, tata letak dapur, lingkungan fisik, fasilitas, dan peralatan dapur yang ergonomis.

Setelah penyampaian materi dilaksanakan maka diberikan bahan diskusi kepada ibu-ibu tersebut untuk kemudian dapat dilakukan pembahasan pada pertemuan berikutnya. Tugas yang diberikan adalah berupa membuat kelompok, memotret dapur salah satu anggota kelompok, mempresentasikan dan mengevaluasinya pada pertemuan kedua.

Pada pertemuan kedua yang dilaksanakan pada 24 Juni 2021 dilakukan penyampaian materi tambahan terkait dengan aplikasi kesehatan dan keselamatan kerja di dapur. Kemudian dilanjutkan dengan mendengarkan pemaparan yang dilakukan oleh ibu-ibu PKK terkait masing-masing dapurnya melalui foto. Pada saat pemaparan, dilakukan juga pendampingan oleh dosen-dosen dari KBK Perancangan Produk dan Ergonomi. Ibu-ibu PKK Kelurahan Sukawarna Kecamatan Sukajadi Kota Bandung menyampaikan secara antusias mengenai hasil pengkajian studi kasus area dapur kelompok mereka masing-masing, dan diberikan masukan lain dari Dosen-dosen KBK Perancangan Produk dan Ergonomi. Beberapa hasil kajian terkait studi kasus yang ditemukan adalah tinggi meja kerja sampai peralatan dapur yang kurang memenuhi persyaratan ergonomi sehingga kurang nyaman digunakan oleh pemiliknya dan cepat menimbulkan kelelahan dan keluhan subjektif, tinggi lemari penyimpanan beberapa diantaranya dibuat tanpa memperhitungkan ukuran yang tepat sehingga sulit dijangkau dari pemiliknya, sirkulasi udara yang tidak di maksimalkan (tidak selalu dibuka oleh pemiliknya karena tertutup oleh kain) menyebabkan pergantian udara luar dengan udara dalam menjadi terhambat, tata letak yang kurang optimal seperti area cuci yang terlalu sempit dan terlalu berdekatan dengan area memasak, tinggi area cuci yang terlalu rendah sehingga menyebabkan postur membungkuk pada saat bekerja, tempat penyimpanan obat pembunuh serangga yang terlalu dekat dengan kompor sehingga beresiko terjadinya ledakan, tempat penyimpanan air minum yang terlalu tinggi di atas alat elektronik seperti kulkas sehingga sulit dijangkau. Postur kerja merupakan salah satu cara penentu keefektifan kerja. Jika seseorang, mudah mengalami kelelahan dalam bekerja maka hasil pekerjaan tersebut akan mengalami penurunan dan tidak sesuai dengan yang diharapkan [10]. Perlunya memperhatikan faktor ergonomi dalam proses rancang bangun fasilitas dalam dekade ini merupakan proses yang tidak dapat ditunda lagi. Hal ini tidak terlepas dengan pembahasan ukuran anthropometri tubuh maupun penerapan data dimensi tubuh sebagai bentuk penerapan anthropometri ini. [11].

Dari hasil diskusi pada pertemuan ini, ibu-ibu PKK kelurahaan mendapat masukan terkait perbaikan dapur yang ergonomis. Pada pertemuan kedua jelas terlihat bahwa ibuibu PKK mulai memahami terkait konsep ergonomi dapur. Hal ini dapat terlihat dari survei yang dilakukan pada akhir pertemuan, jawaban yang diberikan memiliki tingkat akurasi yang lebih tinggi dari sebelumnya. Suasana pelaksanaan pengabdian masyarakat pada hari kedua dapat dilihat pada Gambar 2. Hasil survei akhir dapat terlihat di 
Tabel 3, dimana dari beberapa pertanyaan yang diberikan, hampir semua peserta dapat memberikan jawaban yang tepat.

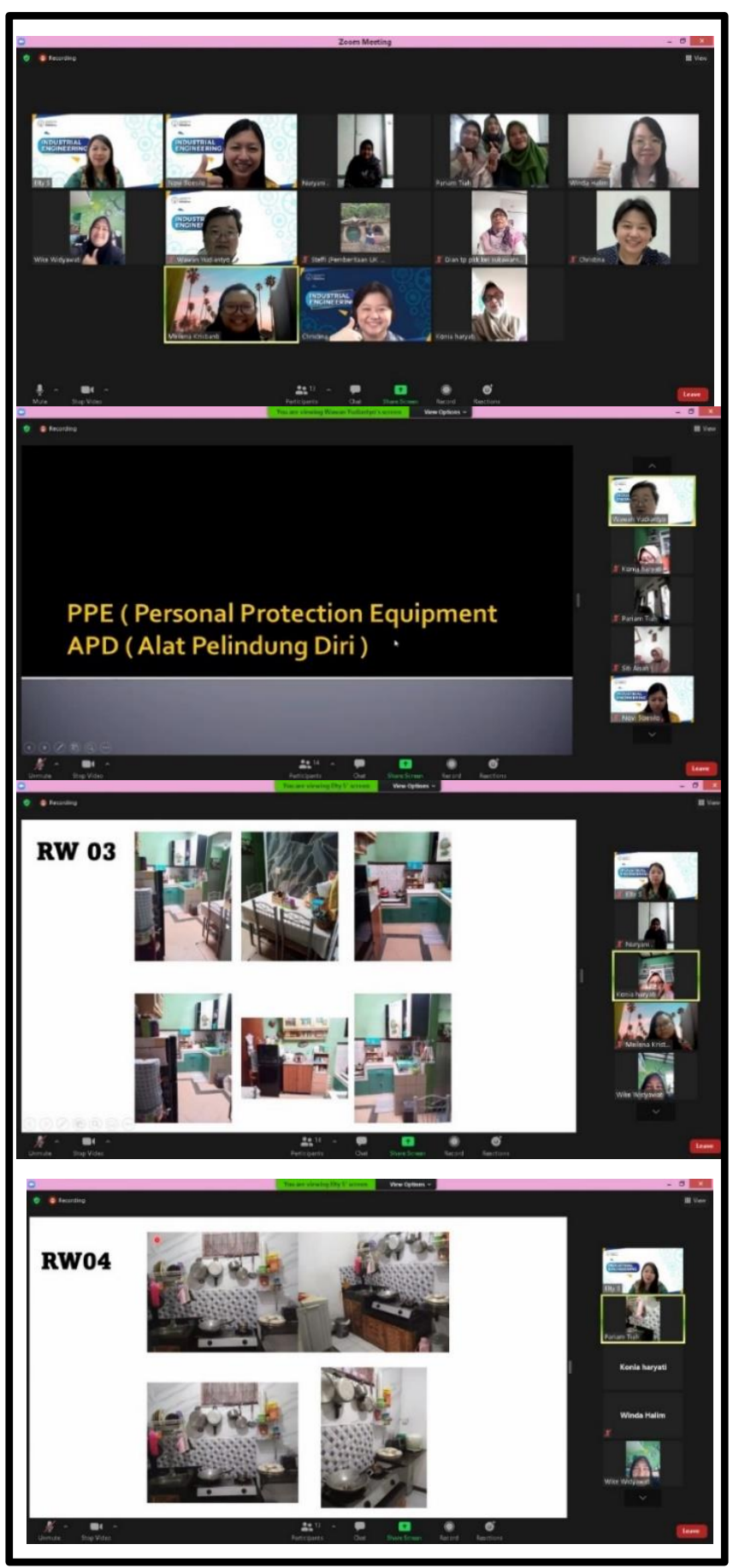

Gambar 2. Pelaksanaan Hari Kedua (24 Juni 2021)

TABEL 3

PROSENTASE JAWABAN BENAR

\begin{tabular}{|c|l|c|c|}
\hline No & \multicolumn{1}{|c|}{ Pertanyaan } & $\begin{array}{c}10 \text { Juni } \\
2021\end{array}$ & $\begin{array}{c}24 \text { Juni } \\
2021\end{array}$ \\
\hline 1 & $\begin{array}{l}\text { Apa yang dimaksud dengan } \\
\text { Ergonomi }\end{array}$ & $0 \%$ & $14 \%$ \\
\hline 2 & $\begin{array}{l}\text { Apakah yang menjadi fokus } \\
\text { perancangan dalam ergonomi }\end{array}$ & $67 \%$ & $71 \%$ \\
\hline 3 & $\begin{array}{l}\text { Berdasarkan Ilmu Ergonomi, apa } \\
\text { yang harus kita perhatikan dalam } \\
\text { merancang produk? }\end{array}$ & $33 \%$ & $57 \%$ \\
\hline 4 & $\begin{array}{l}\text { Hal-hal yang perlu diperhatikan } \\
\text { dalam merancang dapur yang } \\
\text { ergonomis? }\end{array}$ & $73 \%$ & $100 \%$ \\
\hline 5 & $\begin{array}{l}\text { Saat menyimpan peralatan elektrik } \\
\text { di dapur harus memperhatikan? }\end{array}$ & $93 \%$ & $100 \%$ \\
\hline 6 & $\begin{array}{l}\text { Apa yang perlu diperhatikan dalam } \\
\text { penggunaan tabung gas? }\end{array}$ & $40 \%$ & $100 \%$ \\
\hline 7 & $\begin{array}{l}\text { Apa yang perlu diperhatikan dalam } \\
\text { perancangan lingkungan fisik di } \\
\text { area dapur? }\end{array}$ & $20 \%$ & $86 \%$ \\
\hline Rata-rata persentase jawaban benar & $\mathbf{4 7 \%}$ & $\mathbf{7 6 \%}$ \\
\hline
\end{tabular}

\section{Prosentase Jawaban Benar}

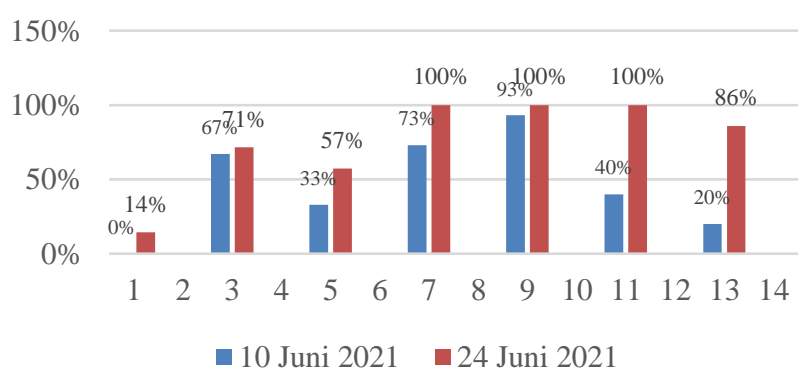

Gambar 3. Prosentase Jawaban Benar terkait Ilmu Ergonomi Ibu-ibu PKK Kelurahan

Pada Tabel 3 dapat terlihat bahwa setelah dilakukannya penyampaian materi dan diskusi, peserta menjadi jauh lebih memahami tentang konsep ergonomi dapur dan aplikasinya. Berdasarkan hal tersebut maka harapan agar ibu-ibu dapat memahami konsep ergonomi dapur dan aplikasinya, yang merupakan target dari pengabdian masyarakat ini dapat tercapai (dapat dilihat dari Gambar 3). Pemahaman yang dimiliki tentunya diharapkan dapat diterapkan lebih lanjut di dapur rumahnya masing-masing. Dampak jangka panjang yang tentunya diharapkan adalah ibu-ibu dapat bekerja di dapur dengan aman, sehat, nyaman, efektif, dan efisien. Dengan memahami konsep ergonomi dapur, maka akan memberikan manfaat keselamatan dan kesehatan juga mengurangi kelelahan berlebihan saat berkerja di dapur [12].

\section{KESIMPULAN DAN SARAN}

Berdasarkan hasil survei awal dan akhir terjadi kenaikan pemahaman yang dimiliki oleh peserta. Peningkatan tersebut dapat menjadi bukti bahwa pendekatan edukatif 
dan partisipatif yang diterapkan berhasil untuk mempermudah penerimaan dan penyerapan informasi kepada peserta yang notabene adalah ibu rumah tangga biasa. Melalui pengabdian masyarakat ini juga dapat diketahui bahwa masih minimnya ketersediaan informasi untuk dapat ibu-ibu bekerja di dapur maupun tempat lainnya secara lebih ergonomis. Sehingga, tentu perlu adanya penyuluhan lanjutan yang diberikan terkait dengan tempat atau aktivitas lain di rumah.

\section{UCAPAN TERIMA KASIH}

Ucapan terima kasih diberikan Ibu-ibu PKK Kelurahan Sukawarna Kecamatan Sukajadi Kota Bandung dan, Ibu Christina S.T., M.T (ketua Program Studi Teknik Industri Universitas Kristen Maranatha, Bandung) yang telah memfasilitasi kegiatan acara ini.

\section{DAFTAR PUSTAKA}

[1] T. F. A. G. Atmadja, A. E. Yunianto, E. Yuliantini, M. Haya, A. Faridi and Suryana, "Gambaran Sikap dan Gaya Hidup Sehat Masyarakat Indonesia Selama Pandemi Covid-19," AcTion: Aceh Nutrition Journal, pp. 195-202, 2020.

[2] B. Martono, "Bagaimana Merancang Dapur Rumah yang Ergonomis?," 2015.

[3] K. Shete, H. T. Pandve and T. Puntambekar, "Role of Ergonomics in Kitchen Related Back Problem," Journal of Ergonomics, 2015.

[4] R. Yared, B. Abdulrazak, T. Tessier and P. Mabilleau, "Cooking Risk Analysis to Enhance Safety of Elderly
People in Smart Kitchen," in PETRA'15: Proceedings of The 8th ACM International Conference on Pervasive Technologies Related to Assistive Environments, Quebec, 2015.

[5] "Reduce Workplace Hazards: Norris," 12 Juli 2021. [Online]. Available: https://norris.com.au/reduceworkplace-hazards.

[6] I. Hardianto and Yassierli, Ergonomi Suatu Pengantar, Bandung: PT. Remaja Rosdakarya, 2014.

[7] C. Wickens and J. Hollands, An introduction to Human Factors Engineering 2nd Ed., New Jersey: Prentice Hall, 2004.

[8] K. Kroemer, Engineering Anthropometry. In W. Karwowski, W. S. Marras (Ed.), Occupational Ergonomics:Pterprinciples of Work Design, Boca Raton: CRC Press, 2003.

[9] P. Salim, "Intervensi Ergonomi Terhadap Kenyamanan Bekerja di dapur Rumah Tinggal," Humaniora, pp. 238$245,2014$.

[10] L. Susanti, H. R. Zadry and B. Yuliandra, Pengantar Ergonomi Industri, Padang: Andalas University Press, 2015.

[11] E. Nurmianto, Ergonomi, Konsep Dasar dan Aplikasinya, Surabaya Indonesia , Institut Teknologi Sepuluh Nopember: Penerbit Guna Widya, 2008.

[12] F. H. Ismail, S. Osman and F. B. A. Rahman, "Ergonomics Kitchen: A Better Place to Work," International Journal of Academic Research in Bussiness and Social Sciences, 2021. 